\title{
Learning Flows: Understanding How Older Adults Adopt and Use Mobile Technology
}

\author{
Extended Abstract ${ }^{\dagger}$ \\ Xiying Wang \\ Pennsylvania State University \\ University Park, PA \\ U.S.A. \\ xiyingwang@psu.edu \\ Tiffany Knearem \\ Pennsylvania State University \\ University Park, PA \\ U.S.A. \\ tak54@psu.edu
}

\author{
John M. Carroll \\ Pennsylvania State University \\ University Park, PA \\ U.S.A. \\ jmcarroll@psu.edu
}

\begin{abstract}
In recent years ${ }^{1}$, the number of older adults who own a smart mobile device, such as a smartphone or tablet, has increased. However, the popularized idea that older adults are uninterested in or do not care to use mobile technology is still prevalent in today's society. In this paper, we conducted 12 semi-structured interviews with older adults to understand their health and wellbeing through the lens of adapting to and learning how to use mobile technology. We found that older adults, upon acquiring a smart mobile device, were motivated to familiarize themselves with it. Moreover, they supported each other in their endeavors to become familiar with technology. We conclude that older adults are positively influenced by the process of adapting to and using new technologies.
\end{abstract}

\section{CCS CONCEPTS}

- Human-centered computing $\rightarrow$ Human computer interaction (HCI); Empirical studies in $\mathrm{HCI}$

\section{KEYWORDS}

Active aging, mobile technology, learning, older adults

\section{ACM Reference format:}

X. Wang, T. Knearem, J. Carroll. 2018. Learning Flows: Understanding How Older Adults Adopt and Use Mobile Technology. In Proceedings of the 12th EAI International Conference on Pervasive Computing Technologies for Healthcare (PervasiveHealth'18). ACM, New York, NY, USA, 4 pages. https://doi.org/10.1145/nnnnnnn.nnnnnnn

\footnotetext{
*Produces the permission block, and copyright information

tThe full version of the author's guide is available as acmart.pdf document ${ }^{1}$ It is a datatype.

Permission to make digital or hard copies of part or all of this work for personal or classroom use is granted without fee provided that copies are not made or distributed for profit or commercial advantage and that copies bear this notice and the full citation on the first page. Copyrights for third-party components of this work must be honored. For all other uses, contact the owner/author(s). PervasiveHealth'18, May 2018, New York, NY, USA

(c) 2018 Copyright held by the owner/author(s). 123-4567-24-567/08/06 . . \$15.00 https://doi.org/10.1145/nnnnnn.nnnnnn
}

\section{INTRODUCTION}

Mobile phone ownership has rapidly increased in recent years. In particular, the adoption of smartphones and smart tablets by older adults (65 years old and older) continues to grow. About 4 in 10 older adults own and use a smart mobile device (42\%), whereas only $18 \%$ of older adults owned a smart mobile device in 2013 [1].

Previous research suggests that using mobile technology greatly supports older adults' health and well-being [2]. The most common use case for mobile technology is to allow medical professionals and family members to keep track of older adults' activities. In particular, mobile phones can facilitate personal tracking and monitoring of older adults daily activities, such as tracking their outdoor activities to prevent potential falls [7]. Besides helping older adults cope with physical declines, mobile phones can also help them manage declining mental capacity. For example, Leo et al. designed a mobile application that automatically took pictures to document older adults' life every five minutes [4]. They found that mobile phones could help older adults cope with memory loss by presenting those pictures back to them [4].

However, all those practices consider older adults from a deficits perspective [3]. In other words, older adults are dependent on the mobile technology to support their health and well-being. This approach is often referred to as problem-driven design, where mobile technology is considered as an external tool to solve health issues of older adults.

Conversely, there is another approach to understanding older adults - that of active and positive aging, where older adults can take initiative to promote their health and well-being. In this approach, technology is considered as a way to facilitate older adults' endeavors to achieve healthy aging. Supporting positive activities in life, such as volunteering [3], socializing [6], and learning [8] can play an important role in promoting health and well-being.

Using the active aging approach, we aim to understand active aging through the lens of using and adapting to mobile technology. We conducted 12 semi-structured interviews with older adults to explore the following research questions: 1) How 
do older adults start to use a mobile device, e.g., a smartphone or a tablet, 2) How do they learn and adapt to the technology, 3) What can motivate them to continue using mobile technology, and 4) How does the adapting and learning process influence their health and well-being.

\section{METHOD}

To understand how older adults naturally used mobile technology in their life, we conducted an interview study with 12 participants. All participants were healthy adults aged 65 years old or above. Each participant owned at least a smartphone (e.g., iPhone or Android phone) or a tablet (e.g., iPad).

\subsection{Recruitment}

We used snowball sampling to recruit participants from local senior centers and local community groups in a medium-size city located on the East Coast of the United States. First, we asked the older adults whether they were interested in having a conversation with us about their mobile technology use and answered any questions they had. Based on their responses, we carefully selected 12 participants who met with the following criteria: 1) healthy adults aged 65 years old and above, 2) must own at least one of the following mobile devices: a smartphone or a tablet.

\subsection{Participants}

Most of the participants were female ( 9 out of 12) and three were male (see Table 1). Of those participants, seven were in a marital relationship, three in a dating relationship, one was widowed, and one was single. Half of the participants (6 out of 12) were living by themselves and the remaining six were living with their family. Almost all of the participants (11 out of 12) had at least a son or a daughter, except one did not have any child.

Table 1. Participants demographics.

\begin{tabular}{l|l|l|l} 
Participant & Gender & $\begin{array}{l}\text { Marital } \\
\text { Relationship }\end{array}$ & Children \\
\hline P1 & Female & Married & A son \\
\hline P2 & Male & Married & A daughter \\
\hline P3 & Female & Divorced & $\begin{array}{l}\text { A son and two } \\
\text { daughters }\end{array}$ \\
\hline P4 & Female & Divorced & $\begin{array}{l}\text { A son and a } \\
\text { daughter }\end{array}$ \\
\hline P5 & Female & Widowed & Three daughters \\
\hline P6 & Female & Single & None \\
\hline P7 & Female & Married & $\begin{array}{l}\text { A son and a } \\
\text { daughter }\end{array}$ \\
\hline P8 & Male & Married & $\begin{array}{l}\text { A son and a } \\
\text { daughter }\end{array}$ \\
\hline P9 & Female & Married & A son \\
\hline P10 & Male & Married & A son \\
\hline P11 & Female & Married & A son \\
\hline P12 & Female & Divorced & Two daughters
\end{tabular}

\subsection{Study Procedure and Analysis}

We conducted 12 semi-structured interviews to understand older adults' use of mobile technology, particularly how they started to use mobile technology and how they adapted to the use of mobile technology. For example, we asked questions about how they started to use their mobile device, how they learned to use it, and how mobile devices played a role in their life. Each interview lasted from an hour to three hours, and took place at a location that was convenient for the participant, e.g., the participant's house or a private room at the senior center.

All interviews were transcribed. Four researchers iteratively coded all the interviews using the following procedures. First, we coded the first five interviews and generated a list of codes. Second, we cleaned the codes using a standard format. For example, we used "interest group: share knowledge" to represent sharing information and knowledge across an interest-based group to which an older adult belonged. Then we used the new codes to recode the first five interviews and to code the rest of the interviews. We added new emergent codes when new activities or phenomenon occurred. Last, we organized all the codes into themes with participants' quotations and researchers' memos.

In this paper, we present an important part of the analysis on use of mobile technology rather than report every insight from the analysis. Readers should keep in mind that there are other insights from our analysis that are outside the scope of this paper. We only report on the insights that directly relate to use of mobile technology.

\section{FINDINGS}

Our interviews suggest that adapting to a smart mobile device was a natural process for older adults, which often started when they were gifted the device by a family member. Once familiar with their device, older adults often took the initiative to continue to learn how to use it. They would then share their knowledge and support their peers in the use of mobile technology. Through this, we discovered three themes, which constitute what we term "knowledge flows": the learning flow, the sharing flow and the supporting flow. Note that "sharing knowledge" refers to how older adults either give or receive information about mobile technology, or their role as a provider of knowledge to others and receiver of it from others.

We noticed that older adults often learned to use a smartphone or a tablet from their family members. We call this the learning flow, where older adults were the active learners who received support from their family to learn mobile technology. Oftentimes, older adults not only learned from their family, but they also actively shared what they learned with other older adults who were their friends or acquaintances. We term this the sharing flow. In this flow, older adults who had already learned about their device, taught others how to use their device. Finally, we found that older adults supported their friends to use mobile technology by encouraging them to learn new things about their device on their own. We call this the 
supporting flow. In the following section, we discuss the three knowledge flows and the role of older adults' in each flow.

\subsection{Learning Flow: Active Learners}

Of all the older adults who had at least one child (11 out of 12), they all began to use their smartphone or tablet when their adult child purchased one for them. For example, P1 regularly used her iPad in her daily life after her son gave it to her.

"That's because my son gave me the iPad, got me started." (P1, female)

Similarly, other participants also mentioned that they started to use their smartphone or tablet when it was given to them. In particular, they started to try and learn different applications on their device from their family members. For example, P4 told us that her daughter encouraged her to use a mobile banking app to manage her accounts. She was pleasantly surprised with the ease of managing her bill payments with the mobile app.

"My daughter got me onto banking... And I didn't think I'd like it. I'd go, 'No, no,' but I really do like it. You can watch, you can see everything." ( $\mathrm{P} 4$, female)

Later, she mentioned that she was motivated to learn how to use other mobile apps from her daughter, since she had mastered this mobile app. For example, she became proficient in using the Amazon app to shop for items on her Android phone. At the time of the interview, she just started learning how to use the Facebook app, because her daughter set up a Facebook account for her.

Special deals, family communication, and entertainment are three important factors that motivated older adults to learn to use their smartphone. For example, P12 found out that some bus tickets were cheaper when purchased online. This motivated her to learn how to use the bus companies mobile system to view and purchase bus tickets. P10 and P11 were a couple; each had an iPad of their own. P10 liked to use his iPad for news and videos. He learned how to follow his favorite TV channels under his son's instruction. His wife (P11) often used it to communicate with her sister in Korea. P10 told us that right after his wife got her iPad, she tried to use FaceTime with her family in Korea. Then their son taught her how to use a social media app called Line, which was widely used in Korea. Gradually, his wife developed a habit of using her iPad to communicate with her family and friends in Korea.

"And she gets Korean news every morning on her iPad and communicates with, she has a sister still living in Korea, many friends, she still communicates with them." (P10, male)

On the opposite side, P6 was single, and did not have children. She often found it difficult to learn about mobile devices. She purchased a second-hand tablet, but she was often frustrated with the tablet because she had no family members that she could learn from.
"You have to be driven to continue. And many seniors, especially those who do not have family. If they don't have a support system...The people who come in for computer classes, who have their little laptops and their iPads and all that are more affluent individuals, and they always have grandchildren, because it is the grandchildren that teach them how to do it. I have no young people in my life anymore." (P6, female)

From our interviews, we found that family, especially younger family members like sons and daughters, are often the initial supporters for older adults when it comes to learning how to use smart mobile devices. They became motivated to learn how to use the smart mobile devices for a variety of reasons. Getting special deals, maintaining communication with others, and entertainment are the three motivating reasons that older adults gave for learning how to use mobile technology.

\subsection{Sharing Flow: Partakers in Knowledge}

Our interviews also suggested that older adults were active in sharing information about mobile technology with their peers. Of those who were engaged in a hobby group (8 out of 12), they often exchange new things they learned about mobile devices, e.g., new mobile apps. We call this phenomenon the sharing flow, where older adults take on both the learner and teacher role amongst their peers.

For example, P1 started to use the Pinterest app after her knitting group introduced it to her. One of the group members introduced Pinterest to the others and showed to the group how to find different knitting-related posts and ideas on Pinterest. Gradually, P1 became proficient in using Pinterest to search for knitting inspirations. She customized her profile, organized knitting ideas, and save those ideas to her email.

"Somebody at knitting group told me [about Pinterest]... we each bring different information to each other." (P1, female)

"It comes up with a basic search and then you can search... What I've saved to the boards, and that's what I mean. I have crafts, knitting, crocheting, and quilting, stuff like that. I look and see what's new and save what I like and send what I like to my email." (P1, female)

She often looked for knitting ideas suitable for her peers and shared the ideas at the local senior center. P1 also introduced Pinterest to her peers and taught them how to use it. As a result, an 80-year old and a 90-year old from the senior center developed an interest in Pinterest for knitting because of P1. They eventually formed a "knit and Pinterest" group at the senior center.

\subsection{Supporting Flow: Problem-solvers}

To some participants ( 8 out of 12 ), they were ready to help their peers even they did not how to use mobile device themselves. Helping other older adults to solve a technology-related issue was often the motivation for them to learn the mobile technology with which they were not familiar. 
For example, P3 often searched for instructions on her tablet to help her friend. She told us a story about when her friend (also an older adult) wanted to apply for a passport online. However, her friend did not know how to do it. Without prior experience in the online passport process, P3 searched for information about passport application on her tablet, followed the instructions, and successfully helped her friend to submit an application form.

"My friend will say, 'What about?' I'll say, 'Well, I'll look it up.' So I just type in what he wants to know, and I look it up. Make applications for passports and I can do that kind of stuff." (P3, female)

Similarly, other participants mentioned that they sometimes would figure out mobile technology, e.g., the Facebook app, to help others use an unfamiliar feature. When P8 and his friend (another older adult) went out for lunch, they were trying to post photos to their Facebook timelines. Neither of them were familiar with Facebook, but P8's friend really wanted to post photos to his Facebook. P8 managed to figure it out at the end and taught his friend how to do it. He was proud of himself because he figured it out and was able to help his friend post photos on Facebook.

\section{DISCUSSION}

While it may be a common belief that older adults don't understand or avoid using mobile devices, our interviews suggest that older adults actively engage in learning and supporting their peers in smart mobile device use.

Many older adults got started on mobile technology because their children gifted them a device. They then engaged in further technology use with peers or through their hobbies. We believe that active engagement in learning about, using, and teaching peers how to mobile devices could promote healthy aging. In this process, family and peer support could play an important role in motivating older adults to continue to pursue new uses of mobile technology. For example, many older adults start to learn and use a smartphone only after receiving one from their children. They also then learn from each other to improve their knowledge of mobile apps. Besides serving in a learner role, older adults also engaged themselves in teaching peers or helping them to deal with confusion around mobile technology. These collaborative and supportive learning processes in turn made them more active in pursuing additional knowledge of mobile technology, and facilitated a positive attitude towards mobile technology. All of the activities involved within these processes, such as socializing and sharing, kept the older adults active, which can be seen as a contributing factor in healthy aging.

\section{CONCLUSION}

In this study, we discussed how adapting to and using mobile technology can play an important role in healthy aging. Many older adults start to use mobile devices, such as a smartphone or tablet after being gifted the device by an adult child.. They were motivated to learn more about how to use their mobile device through hobby groups and their peers. Lastly, they also actively engaged in learning how to use unfamiliar mobile apps or features in order to support their peers understanding of mobile devices, thus increasing their own knowledge in the process. These varied learning activities can motivate older adults to stay mentally active and support others to learn as well, which positively impacts older adults' health and well-being.

In the next step, we will conduct additional interviews and continue the data analysis process with the aim of further unpacking how older adult's health and well-being relates to mobile technology. We are also planning to design and prototype several mobile applications to better support smart mobile device learning.

\section{ACKNOWLEDGMENT}

We thank our interviewees for their time and participations in the study. We also thank Theodore Lee and our anonymous reviewer for the insightful feedback. This work is supported by National Science Foundation (NSF) Smart and Connected Health grant \#1502176.

\section{REFERENCES}

[1] Monica Anderson and Andrew Perrin. 2017. Technology use among seniors. http://www.pewinternet.org/2017/05/17/technology-use-among-seniors/. Retrieved on April $5^{\text {th }} 2018$.

[2] Holly Blake. 2008. Innovation in practice: mobile phone technology in patient care. British journal of community nursing, 13(4),160-165.

[3] John M. Carroll, Gregorio Convertino, Umer Farooq, and Mary Beth Rosson. 2012. The firekeepers: aging considered as a resource. Univers. Access Inf. Soc. 11(1), 7-15.

[4] Gianluca De Leo, Eleonora Brivio, and Scott W. Sautter. 2011. Supporting autobiographical memory in patients with Alzheimer's disease using smart phones. Applied neuropsychology, 18(1), 69-76.

[5] Jonathon Joe and George Demitris. 2013. Older adults and mobile phones for health: a review. Journal of Biomedical Informatics, 46, 947-954.

[6] Amanda Lazar, and David H. Nguyen. 2017. Successful Leisure in Independent Living Communities: Understanding Older Adults' Motivations to Engage in Leisure Activities. In Proceedings of the 2017 CHI Conference on Human Factors in Computing Systems (CHI '17), 7042-7056.

[7] Frank Miskelly. 2004. A novel system of electronic tagging in patients with dementia and wandering. Age and ageing, 33(3), 304-306.

[8] John W. Rowe, and Robert L Kahn. 1997. Successful Aging. The Cerontologist, 37(4), 433-440. 